\title{
Providing a Protection against Ultraviolet Lights Indoors via Cotton Textiles
}

\author{
Nigar MERDAN ${ }^{1}$, Seyda CANBOLAT ${ }^{1}$, Filiz AKIN² \\ ${ }^{1}$ Istanbul Commerce University, Faculty of Engineering and Design, Department of Fashion and Textile, Istanbul, Turkey \\ ${ }^{2}$ Abant Izzet Baysal University, Vocational High School, Bolu, Turkey
}

\begin{abstract}
Apart from the special glasses used for the building pockets, almost all of the glasses are permeable against the ultraviolet lights. Therefore it is more practical and economical to provide protection against ultraviolet lights via curtains in the fronts instead of special glasses. In this study; the ultraviolet protection fabrics of the $100 \%$ cotton woven fabric, which is raw, bleached, dyed without being applied ultraviolet absorbent and dyed after being applied ultraviolet absorbent in different concentration. According to the results, it was determined that a prefect protection can be enabled indoors by using ultraviolet absorbent, and the results showed that the ultraviolet protection increases with increase in the concentration of ultraviolet absorbent in the samples.
\end{abstract}

Keywords: Cotton Woven Fabric, Indoor Textiles, Ultraviolet Absorber, Ultraviolet Protection Factor.

\section{INTRODUCTION}

A commercial sharing of experiences in the fields of textile and architecture carries the textiles used indoors one step further in terms of aesthetics and functionality. The first function of the curtains, which are used multi-purposefully in interior decoration, keeps the degree of the daylight in a place under control. While a cover is provided via the curtains that separate the indoors and outdoors, there is also a protection against daylight during daytime.

Using a quality and healthy fabric indoors is important since it will affect the inner atmosphere of fabric structure. In terms of structure biology; the features of the building materials are important as well as the features of the indoor textiles used indoors intensely. In accordance with this awareness recently, it is paid attention that the curtain fabrics used indoors for wide meter square areas are natural and have protection against the impacts of the sun.

Ultraviolet Protection Factor is a measurement for the protection that a fabric provides against UVR. When a direct light falls on the fabric a part of the radiation is reflected, some part of it is absorbed by the material and another part of it transmits through the fabric. The amount of radiation transmitting through the material is stated as spectral transmittances $(\mathrm{T} \lambda)$. Transmittance spectrum show the features of a fabric that has certain characteristics [1].

The UV absorbents, which are applied in order to provide a protection for the fabric, are materials of organic (o-hidroksibenzofenon, o-hidroksifenilbenzotriazol, o-hidroksifeniltriazin structures) and inorganic (such as titanium dioxide) structure that have the characteristic of absorbing the UV radiation at a very high rate and sending the absorbed energy back without damaging the environment and a syntheses of the UV absorbents is being developed in new structures and formulations today[2-6]. Elements such as fibres within the component of the fabric, the additive agents of the fibres, structural features of the fabric, its colour and colour intensity, washing / drying conditions of the clothes, tension and humidity rate are factors that affect transmittance spectrum $[2,7]$.

There are many studies, in which UV absorbents in various structures are used in order to protect polymers against UV radiation, being conducted. In these studies the effects of fibre type, weaving, lattice structure and colorants used on the UV protection feature are included [8-11]. There are studies, in which the UV absorbents are used in order to develop the light fastness in dyeing the cotton threads with natural dye [12], UV absorbents are applied in printing paste in the printing of the mixtures of cellulosic material with wool [13], effects of the bio polishing and UV absorbers

Corresponding Author: Seyda CANBOLAT, Tel: +90 (212) 51141 88, E-mail: scanbolat@ticaret.edu.tr

Submitted: 15 October 2014, Revised: 04 March 2015, Accepted: 01 July 2015 
on the UV protection features of the woven cotton fabrics, included in the literature [14].

\section{MATERIAL AND METHOD}

\subsection{Material}

In the UV absorbent applications of the woven fabric that is acquired by using a Ne10/2 number $100 \%$ cotton thread and that has $270 \mathrm{~g} / \mathrm{m} 2$ weights Rayosan C (Clariant) is used while Procion Brillant Red HE-GXL (DyStar) reactive colorant is used for the dyeing procedures. \% transmittance values of the fabrics are measured via Lambda 9 Perkin Elmer UV visible area spectrophotometer.

\subsection{Method}

While sodium sulphate $(70 \mathrm{~g} / \mathrm{L})$ is added to the solution in $30^{\circ} \mathrm{C}$ that has a solution rate of $1 / 50$, the material underwent a process in this solution for 10 minutes afterwards. Late in a different concentration, after working with the UV absorbent material $(\mathrm{y} \%$ concentration $=0 \%, 1 \%, 2 \%$ and $4 \%$ ), in the same temperature for 10 minutes, sodium carbonate is added to the solution, $\left[(2+\mathrm{y}) \% \mathrm{Na}_{2} \mathrm{CO}_{3}\right]$ and it was worked for another 30 minutes, then the material was rinsed and dried. For the control of the process, every application was repeated for three times.

After the UV absorbent application, another dyeing solution that has a $1 / 10$ solution rate was prepared and the colorant $(0.1 \%)$ and dyeing auxiliaries $\left(180 \mathrm{~g} / \mathrm{l} \mathrm{NaCl}+20 \mathrm{~g} / 1 \mathrm{Na}_{2} \mathrm{CO}_{3}\right)$ were added to the solution in the beginning of the dyeing. The dyeing was done for 80 minutes in $60^{\circ} \mathrm{C}$, and afterwards overflow cold, hot washing, boiling soaping and cold rinsing procedures are applied.

$\%$ transmittance measurements of the fabrics are applied accordingly with the AS/NZS 4399: 1996 standards via UV visible area spectrophotometer. The UVR transmittance of each sample from $290 \mathrm{~nm}$ to $400 \mathrm{~nm}$ with $5 \mathrm{~nm}$ intervals was measured and UPF of each sample was calculated according to the formula (Formula 1) stated in the same standard [15].

$\mathrm{UPF}=\frac{E_{e f f}}{E^{*}}=\frac{\sum_{\zeta<3}^{733} E_{\lambda} x S_{\lambda} x \Delta \lambda}{\sum_{\zeta<3}^{733} E_{\lambda} x S_{\lambda} x T_{\lambda} x \Delta \lambda}$

$\mathrm{E} \lambda=$ Relative eritemal Spectral effect

$\mathrm{S} \lambda=$ spectral radiation of the sun (W.m -2.nm-1)

$\mathrm{T} \lambda=$ spectral transmittance of the material
$\Delta \lambda=$ wavelength steps (as $\mathrm{nm}$ )

$\Lambda=$ wavelength, $\mathrm{nm}$

The arithmetic mean of the UVA and UVB transmittance is calculated on the basis of the formula (Formula 2) stated in the same standard.

$\mathrm{UVA}_{\mathrm{AV}}=\frac{T_{315}+T_{320}+T_{325}+\ldots .+T_{395}+T_{400}}{18}$
$\mathrm{UVB}_{\mathrm{AV}}=\frac{T_{290}+T_{295}+T_{300}+T_{305}+T_{310}+T_{315}}{6}$

\section{RESULTS AND DISCUSSION}

In Table 1 , the $\%$ transmittance values of $100 \%$ cotton woven fabric, which is raw, bleached, dyed without being applied UV absorbent but dyed after being applied UV absorbent, in the 290-400 $\mathrm{nm}$ intervals with $5 \mathrm{~nm}$ intervals. In Figure 1, however, the $\%$ transmittance curves which are created with the help of these transmittance values.

Table 1. \% Transmittance Values of the Experiment Samples

\begin{tabular}{|c|c|c|c|c|c|c|}
\hline $\begin{array}{c}\text { Wavelength } \\
\text { (nm) }\end{array}$ & $\begin{array}{c}\text { Raw } \\
\text { fabric }\end{array}$ & $\begin{array}{c}\text { Bleached } \\
\text { fabric }\end{array}$ & $\begin{array}{c}\text { Dyed fabric } \\
\text { without UV } \\
\text { absorber }\end{array}$ & $\begin{array}{c}\mathbf{1 \% \text { UV }} \\
\text { absorbent } \\
\rightarrow \text { Dyeing }\end{array}$ & $\begin{array}{c}\mathbf{2 \% \text { UV }} \\
\text { absorbent } \\
\rightarrow \text { Dyeing }\end{array}$ & $\begin{array}{c}\text { 4\% UV UV } \\
\text { absorbent } \\
\rightarrow \text { Dyeing }\end{array}$ \\
\hline 290 & 4.82 & 3.5 & 1.67 & 1.31 & 1.34 & 1.11 \\
\hline 295 & 5 & 3.98 & 1.61 & 1.36 & 1.24 & 1.21 \\
\hline 300 & 5.19 & 4.59 & 1.53 & 1.45 & 1.11 & 1.37 \\
\hline 305 & 5.33 & 5.15 & 1.44 & 1.67 & 0.95 & 1.51 \\
\hline 310 & 5.5 & 5.65 & 1.64 & 2.21 & 0.89 & 1.64 \\
\hline 315 & 5.63 & 6.18 & 2.42 & 2.71 & 1.21 & 1.76 \\
\hline 320 & 5.86 & 6.59 & 3.91 & 3.26 & 2.10 & 2.02 \\
\hline 325 & 5.84 & 6.81 & 5.79 & 3.75 & 3.52 & 2.23 \\
\hline 330 & 5.97 & 7.19 & 7.66 & 4.12 & 5.29 & 2.43 \\
\hline 335 & 6.08 & 7.53 & 9.12 & 4.6 & 6.96 & 2.80 \\
\hline 340 & 6.21 & 8.06 & 10.47 & 5.49 & 8.42 & 3.44 \\
\hline 345 & 6.42 & 8.56 & 11.41 & 6.52 & 9.53 & 4.37 \\
\hline 350 & 6.56 & 9.02 & 12.27 & 7.57 & 10.39 & 5.19 \\
\hline 355 & 6.77 & 9.47 & 13.15 & 8.11 & 11.45 & 5.72 \\
\hline 360 & 6.95 & 9.85 & 13.74 & 8.5 & 11.77 & 6.04 \\
\hline 365 & 7.17 & 10.32 & 14.46 & 8.7 & 12.51 & 6.13 \\
\hline 370 & 7.5 & 10.88 & 15.14 & 8.8 & 13.15 & 6.33 \\
\hline 375 & 7.86 & 11.44 & 15.87 & 9.03 & 13.89 & 6.60 \\
\hline 380 & 7.78 & 11.48 & 16.06 & 9.21 & 13.95 & 6.53 \\
\hline 385 & 8.01 & 11.83 & 16.58 & 9.51 & 14.47 & 6.76 \\
\hline 390 & 8.3 & 12.2 & 17.05 & 9.9 & 14.92 & 7.06 \\
\hline 395 & 8.52 & 12.49 & 17.46 & 10.26 & 15.31 & 7.43 \\
\hline 400 & 8.79 & 12.81 & 17.78 & 10.76 & 15.63 & 7.79 \\
\hline
\end{tabular}

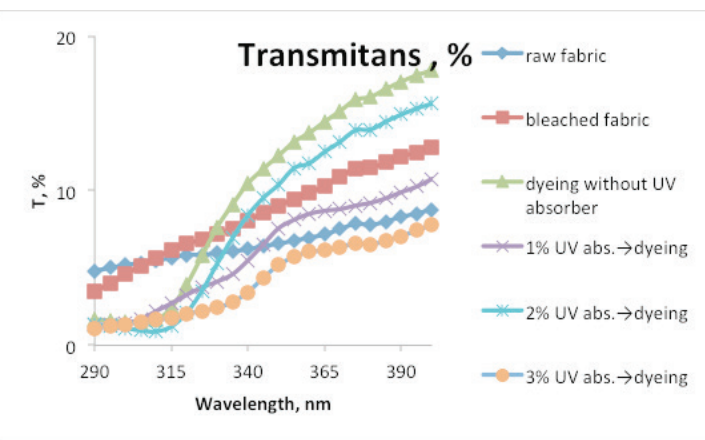

Figure 1. \% Transmittance Values of the Experiment Samples 
95\%-98\% of the ultraviolet radiation (UVR), which is a part of the solar energy reaching the world is comprised of 400-315 nm wavelength UVA, and 2-5\% is comprised of $280-315 \mathrm{~nm}$ UVB. It is known that UVB radiation is far more dangerous for eyes and skin than the UVA and it is responsible of the progress of the skin cancers [16]. As it is seen in Image 1, with the concentration increase of the wavelength in the UVB interval, the UVR permeability decreased and thus the protection against UV increased. Protection against UVB lights is less in the raw and bleached fabric. When the curve of the sample that is dyed without being applied UV absorbent material; it is seen that the colorant enabled protection against radiation in UVB interval but the protection against lights in the 400-315 nm wavelength in UVA interval is low.

In Table 2, ultraviolet protection factor (UPF), UVA and UVB \% values, which are calculated with the help of Formula 1 and 2 by using the values acquired from the \% transmittance measurements of the samples, are given.

Table 2. UPF, UVA $\%$ and UVB $\%$ of samples

\begin{tabular}{lcccc}
\hline & UPF & Classified & UVA $_{\mathbf{A V}}$ & $\mathbf{U V B}_{\mathbf{A V}}$ \\
& & $\mathbf{U P F}$ & $(\%)$ & $(\%)$ \\
Raw Fabric & 17.32 & 15 & 7.01 & 5.25 \\
$\begin{array}{l}\text { Bleached Fabric } \\
\text { Dyed Fabric }\end{array}$ & 15.52 & 15 & 9.60 & 4.84 \\
$\begin{array}{l}\text { 1\% UV absorbent } \\
\text { Dyeing }\end{array}$ & 30.88 & 30 & 12.24 & 1.72 \\
$\begin{array}{l}\text { 2\% UV absorbent } \\
\text { Dyeing }\end{array}$ & 36.25 & 35 & 10.27 & 1.79 \\
$\begin{array}{l}\text { 4\% UV absorbent } \\
\text { Dyeing }\end{array}$ & 44.76 & 40 & 5.04 & 1.43 \\
\hline
\end{tabular}

\section{CONCLUSIONS}

The study, in which the resistance of the cotton shade and curtains to be used indoors against ultraviolet lights are researched;

- It is defined that UPF value is lower in a raw and bleached sample.

- In a dyed sample without containing UV absorbent material; it is seen that the colorant provides protection against UV radiation [17].
- In the samples, which are dyed depending on the remaining UV absorbent material concentration; the UPF values increased linearly and thus the protection features against the ultraviolet radiations of the experiment sample improved.

- As a result in the study that is researched the resistance of the cotton fabric against the ultraviolet radiation; it is determined that a prefect protection can be enabled indoors by using UV absorbent, and it is seen that the protection increases depending on the increase of the UV absorbent material concentration.

\section{REFERENCES}

[1] Böhringer, G., Schindling, G.,Schön, U.,UV-Schutz durch Textilien, Melliand Textilberichte, 7-8, 522, (1997).

[2] Reinert, G., Fuso, F., Hilfiker, R., Schmidt, E., UVProtecting Properties of Textile Fabrics and Their Improvement, Textile Chemist and Colorist, 29 (12) 36-43, (1997).

[3] Cui, Z., Structure and Properties of N-HeterocycleContaining Benzotriazoles as UV Absorbers", Journal of Molecular Structure 1054-1055, 94-99, (2013).

[4] Abeer, I., Novel UV-Protective Formulations for Cotton, PET Fabrics and Their Blend Utilizing Irradiation Technique", European Polymer Journal 45, 2926-2934, (2009).

[5] Ma, W., Synthesis of a Novel Water-Soluble Polymeric UV-Absorber for Cotton, Dyes and Pigments 70, pp. 238-245, (2006).

[6] Czajkowski, W., Synthesis of Reactive UV Absorbers, Derivatives of Monochlorotriazine, for Improvement in Protecting Properties of Cellulose Fabrics, Carbohydrate Polymers, 92, pp.1386-1394, (2013).

[7] Xin, J.H., Daoud, W.A., Kong, Y. Y., A New Approach to UV-Blocking Treatment for Cotton Fabrics". Textile Research Journal, 74 2, 97-100, (2004).

[8] Srinivasan, M., Gatewood, B.M., "Relationship of Dye Characteristics to UV Protection Provided by Cotton Fabric", Textile Chemist and Colorist \& American Dyestuff Reporter, 32 (4), 36-43, (2000).

[9] Paluszkiewicz, J., Czajkowski, W., Kazmierska M., Reactive Dyes For Cellulose Fibres Including UV 
Absorbers, Fibres \& Textiles in Eastern Europe 13 (2), pp.76-80, (2005).

[10] Rupp, J., Böhringer, A., Yonenaga, A., Hilden, J., Textiles for Protection Against Harmful Ultraviolet Radiation, International Textile Bulletin 6, 10, (2001).

[11] Srinivasan, M., Influence of Dyes on the Protection Against Ultraviolet Radiation Provided by Fabrics, PhD Thesis, Kansas State University, Manhattan, pp: 54-60, (1999).

[12] Daniela, C.D., Vilarem, G., Improving Light Fastness of Natural Dyes on Cotton Yarn, Dyes and Pigments 71, 224-230, (2006).

[13] Ibrahim, N.A., Combined UV-protecting and reactive printing of Cellulosic/wool blends", Carbohydrate Polymers, 92, 1386-94, (2013).

[14] Kan W., Au, C.H., Effect of Biopolishing and UV Absorber Treatment on the UV Protection Properties of Cotton Knitted Fabrics, Carbohydr Polymer, 101, 451-6, (2014).

[15] Australia / New Zealand Standard AS / NZS 4399, (1996).

[16] Ed. Scott, R. A., Textiles for UV Protection, Textile Institute, Wood head Publishing Limited, (2005).

[17] Goren ek, M., Sluga, F., Modifying the UV Blocking of Polyester Fabric, Textile Research Journal, 74 (6), 469- 474, (2004). 